\title{
Sonoridades da vida conjugal registradas em versos de canções brasileiras produzidas entre 1940 e 1960
}

\author{
Songs about conjugal life found in verses \\ of Brazilian lyrics produced \\ between 1940 and 1960
}

\author{
Sabrine Mantuan dos Santos COUTINHO ${ }^{1}$ \\ Zeidi Araújo TRINDADE ${ }^{2}$ \\ Maria Cristina Smith MENANDRO ${ }^{2}$ \\ Paulo Rogério Meira MENANDRO²
}

\begin{abstract}
Resumo
O objetivo do presente estudo foi identificar elementos de representações sociais de casamento, marido e esposa, presentes em letras de canções populares gravadas nos anos de 1940 e 1950. Foram selecionadas 306 letras de canções, a partir de consulta a acervos particulares. Na análise dos dados foi utilizado o software Alceste, que apontou a existência de quatro classes, que diferentes formas de discurso acerca das relações conjugais e dos papéis de gênero no casamento, indicando elementos de representações sociais. Um primeiro grupo, constituído pelas classes 1, 3 e 4, pode ser considerado um eixo na organização das representações sociais de casamento, marido e esposa. Esse eixo, aqui denominado Papel feminino e masculino no casamento: real versus ideal, caracteriza-se por apresentar um discurso predominantemente masculino quanto aos aspectos do cotidiano conjugal, com indicações da esposa ideal e da esposa inadequada, retratando o marido como trabalhador/provedor financeiro. Já o outro eixo temático, constituído pela classe 2, tem como tema a desilusão amorosa e a separação. Os resultados exemplificam o papel dos fatores sociais, históricos e culturais na construção das configurações reais com que as relações conjugais são vividas. Apontam, também, como tais relações são orientadas e justificadas por representações sociais flexíveis, associadas aos contextos nos quais foram produzidas, consolidadas e/ou transformadas.
\end{abstract}

Palavras-chave: Casamento; Gênero; Música; Representação social.

\begin{abstract}
The aim of the present study was to identify elements of social representations of marriage, husband and wife, present in popular song lyrics recorded during the 1940s and 1950s. Three hundred and six song lyrics were selected

\footnotetext{
$\nabla \nabla \nabla v$

1 Universidade Federal Fluminense, Instituto de Ciências Humanas e Filosofia, Departamento de Psicologia. Niterói, RJ, Brasil.

2 Universidade Federal do Espírito Santo, Centro de Ciências Humanas e Naturais, Programa de Pós-Graduação em Psicologia. Av. Fernando Ferrari, 514, Goiabeiras, 29075-910, Vitória, ES, Brasil. Correspondência para/Correspondence to: P.R.M. MENANDRO. E-mail: <paulomenandro@uol.com.br>.
} 
from private record collections. The Alceste software was used for data analysis, which pointed towards the existence of four classes that represent different forms of speech about conjugal relations, gender roles in marriage and elements of social representation. Classes 1, 3 and 4 constituted a subgroup that can be considered as an axis in the organization of social representations about marriage, husband, and wife. This subgroup was called Female and Male Role in Marriage: real versus ideal. It is characterized by predominantly male discourse on aspects of conjugal everyday life, indicating the ideal wife and the inadequate one, with the husband being pictured as the worker/financial provider. Class 2 consists of another thematic axis, whose contents cover partner disenchantment and separation. The results exemplify the participation of social, historical, and cultural factors in the construction of the real organization/ arrangement with which conjugal relations are lived, and how such relations are guided and justified by flexible social representations associated with the social contexts in which they were produced, consolidated, and/or transformed.

Keywords: Marriage; Gender; Music; Social representation.

O objetivo da presente investigação foi identificar elementos de representações sociais acerca do relacionamento conjugal heterossexual, de marido e de esposa, presentes em letras de canções brasileiras produzidas e divulgadas nas décadas de 1940 e 1950.

O universo dos relacionamentos conjugais e das configurações familiares no Brasil transformou-se bastante no século XX. Surgiram novas possibilidades no que diz respeito ao casamento, à relação homem-mulher e aos padrões de conjugalidade. Os índices de divórcio, separação e recasamento cresceram, assim como aumentaram as uniões consensuais, substituindo as legalizadas. As mulheres extrapolaram a esfera doméstica, inserindo-se no mercado de trabalho, muitas vezes sendo responsáveis pelo orçamento familiar e pelo gerenciamento dos domicílios (Diniz Neto \& Féres-Carneiro, 2005).

Enfatiza-se que, até pouco tempo atrás, muitas das atuais configurações conjugais e familiares eram impensáveis. Os papéis dos cônjuges no contexto conjugal eram rígidos, com clara divisão entre papéis públicos e privados. Outros tipos de união/casamento que escapavam ao modelo tradicional e legalizado não encontravam legitimidade social.

Retrocedendo na história brasileira, constata-se que o contexto de relacionamento conjugal até os anos 1960 era distinto do atual em vários aspectos. Prevaleciam, ao menos na classe média, as uniões legais, em que o homem era o chefe da família, provedor financeiro e autoridade máxima, e a mulher a responsável pelo lar e pelo cuidado dos filhos e do marido. A realização feminina envolvia o casamento, apesar de já começarem a aparecer posições que apregoavam a possibilidade de a mulher ter emprego e de se dedicar aos estudos, alcançando formação profissional, geralmente com o magistério.

A partir da década de 1960 começaram a ocorrer no Brasil transformações econômicas, políticas, sociais e culturais, decorrentes da intensificação dos processos de industrialização, urbanização e internacionalização do capitalismo, com reflexo efetivo na vida da mulher, na família e na sociedade - mormente na classe média -, atingindo também o casamento, as relações sociais, os comportamentos e as mentalidades.

Quintas (2000) destacou que a mentalidade vigente foi abalada nos anos de 1960, transformando de modo expressivo a vida das mulheres, graças à criação da pílula anticoncepcional, aos movimentos de contracultura, ao ingresso das mulheres no mercado de trabalho e ao crescimento expressivo da presença feminina nas universidades.

É evidente que acontecimentos preparatórios para essas ocorrências dos anos 1960 foram surgindo e amadurecendo nas décadas anteriores. Existem vários indicadores, e eles serão mencionados ao longo do texto, de que nas décadas de 1940 e 1950, no Brasil, ocorreram mudanças embrionárias que iniciaram a abertura de caminhos para concepções novas e menos rígidas a respeito das relações conjugais e dos papéis de esposa e marido.

Ampliar o conhecimento sobre o contexto de relacionamento conjugal nas décadas de 1940 e 1950 revelou-se empreendimento instigante, na medida em que possibilitou perceber a forma como o casamento era compreendido e vivido pelas pessoas em meio aos valores e normas desse momento da história brasileira. Foi possível identificar alguns 
dos papéis masculinos e femininos no contexto familiar e social nesse período, ainda que na fonte de dados utilizada haja mais elementos sobre a condição feminina - sendo importante mencionar que esses elementos foram produzidos sob a ótica masculina -, uma vez que quase todos os compositores das décadas consideradas são homens. Ademais, o estudo propiciou o conhecimento de fatores que, mesmo incipientes e de presença discreta nessa época, podem ter contribuído para mudanças das mentalidades na esfera do relacionamento conjugal. A despeito do já mencionado predomínio de informações sobre a condição feminina, o estudo também propiciou a localização de algumas informações sobre a condição masculina no âmbito conjugal, o que se reveste de especial interesse por serem escassos os estudos que discutem a condição masculina nessa época, especialmente no contexto do casamento, uma vez que, como assinalou Matos (2000), a historiografia de gênero, por muito tempo, privilegiou os estudos sobre mulheres.

Nesta pesquisa, decidiu-se buscar dados sobre relacionamento conjugal a partir de abordagem indireta e documental, valendo-se de letras de canções populares compostas e gravadas nas décadas de 1940 e 1950. Supõe-se que, a partir dessas letras, haveria acesso aos focos de interesse da pesquisa - explicitados no início do texto -, até porque a relação homem-mulher constitui tema recorrente na música popular (Oliven, 1987). A opção foi investigar como maridos e esposas são retratados e valorizados, e quais prescrições de comportamento aparecem nas letras. É possível supor que tais prescrições guardem relação de mútua influência com as práticas cotidianas de homens e mulheres desse período, e também com as experiências de quem compunha tais músicas (homens, em absoluta maioria), possibilitando resgatar um pouco da história desse momento do país.

\section{As canções populares e a "era de ouro" do rádio no Brasil}

A decisão de utilizar como fonte de dados um tipo de produção cultural ainda considerado marginal por algumas correntes da historiografia contemporânea, como as letras de músicas (Matos \& Faria, 1996), parte da compreensão de que um estudo a partir desse tipo de fonte mostra-se de grande riqueza, sobretudo porque a música é capaz de traduzir o pensamento popular de determinada época, representando aspectos do cotidiano de quem as compõe e de quem as ouve, sendo ainda importante manifestação artística e cultural. Beltrão Jr. (1993) enfatizou que "as canções populares fornecem material precioso para análise, já que espelham, dentro de suas características, com grande dose de espontaneidade, o pensamento de um grupo social" (p.42).

Os estudos acadêmicos sobre música popular brasileira ganharam impulso a partir do início dos anos 1990 (Gomes, 1999; Napolitano, 1999). Ainda assim, não são muitas as investigações que utilizaram letras de canções como fontes de dados para a pesquisa social. Alguns exemplos: Almeida Prado (1990); Augras (1998); Beltrão Jr. (1993); Costa (2004); Matos (1997; 1999; 2000); Matos e Faria (1996); Menandro, Pereira, Amim e Santos (2002); Napolitano (2001); Nascimento (2004); Nascimento, Barra e Januário (2008), Oliveira e Marcier (1998); Oliven (1987); Santa Cruz (1992), principalmente, referindo-se à condição feminina e ao casamento.

De acordo com Matos (1997), a produção musical representa "um corpo documental particularmente instigante, já que por muito tempo constituiu um dos poucos documentos sobre certos setores relegados ao silêncio, centrando-se na expressão de sentimentos e abordando temáticas tão raras em outros documentos" (p.29). A autora acrescenta que tal produção, pouco explorada pela análise histórica, constitui rica documentação que pode favorecer a "revelação do cotidiano, das sensibilidades e das paixões, já que todos os dias está na boca de todos" (p.29), afigurando-se como uma das poucas instâncias em que produções culturais de indivíduos da camada popular alcançam difusão pública expressiva.

Muitos artistas da época enfocada no presente estudo afirmavam compor a partir de experiências pessoais, como Lupicínio Rodrigues (Dias, 
1994). Vale destacar também as brigas conjugais públicas e a separação do casal Herivelto Martins, compositor e cantor de sucesso, e Dalva de Oliveira, uma das mais prestigiadas cantoras do país. Suas desavenças conjugais inspiraram várias composições, tanto do próprio envolvido como de amigos da cantora, que, de certo modo, informavam a sociedade e os fãs de todos os detalhes desse dilema conjugal, influenciando e formando opiniões (Vieira \& Norberto, 1992). Recasamentos envolvendo pessoas separadas, como o dos cantores Jorge Goulart e Nora Ney, também geravam discussões que confrontavam tradicionalistas e modernistas quanto aos relacionamentos conjugais (Lenharo, 1995).

É interessante salientar o fato de que as questões conjugais vividas por cantores ou compositores de sucesso confundiam-se, muitas vezes, com suas próprias obras, ampliando o interesse que já despertavam na população em geral. A organização da atividade profissional em torno da música popular exigia certa dose de boêmia, tipo de vida associado a um padrão específico de compreensão da vida conjugal.

Cabe destacar que as canções não atuam impondo valores, nem ditam comportamentos e normas independentemente do contexto mais amplo, assim como não constituem discurso isolado e individual. Ao contrário, elas expressam e generalizam os padrões, valores e sensibilidades de uma época específica, ou seja, do momento histórico-econômico-social-cultural no qual são produzidas, circulam e são consumidas (Matos, 2000).

Oliven (1987) destacou que a música popular brasileira é uma manifestação cultural "especialmente adequada à análise das representações masculinas sobre as relações entre os sexos no Brasil, já que a maioria dos letristas é homem", sendo "uma das únicas instâncias públicas em que o homem se permite falar com sinceridade sobre seus sentimentos em relação à mulher" (p.55). Contudo, Menandro et al. (2002) sugeriram cautela ao se falar em sinceridade em toda forma de música popular brasileira, sendo mais apropriado afirmar que podem existir "distintos matizes de exposição emocional em diferentes grupos de canções" (p.7). Sobre a presença reduzida de compositoras na pro- dução musical da época, um estudo disponível é o de Marques (2000).

Matos (1997) registrou que a produção musical das décadas de 1940 e 1950 mereceu pouca atenção na historiografia da música popular, que tem se centrado sobre os anos 1930, saltando depois para o período da bossa nova (final da década de 1950) e para a produção pós-bossa nova. Não obstante, trata-se de período revelador e instigante em relação ao tema, justificando sua escolha.

Os anos compreendidos entre 1940 e 1960 foram marcados por uma série de acontecimentos em nível nacional e internacional, que tiveram repercussão na vida das pessoas e na forma como elas se relacionavam. De acordo com Faour (2002), particularmente a década de 1950 foi "uma época de profundas transformações na música, na política e no campo das comunicações" (p.12). Para citar apenas um exemplo, pode-se falar na $2^{a}$ Grande Guerra Mundial, nos anos iniciais da década de 1940, cujo fim contribuiu para o aumento do intercâmbio de informações entre os países, o que colaborou para a ocorrência de muitas transformações culturais.

No Brasil, em contexto marcado por transformações e por intensa produção cultural, as transmissões radiofônicas adquiriram importância na vida das pessoas, gerando programas de auditório e publicações especializadas, como a Revista do Rádio, surgida em 1948. Por outro lado, o mercado fonográfico se expandiu, com a penetração das gravadoras internacionais, especialmente as estadunidenses, e do cinema - criticado por conservadores por trazer más influências para as moças (Bassanezi, 2002).

As décadas de 1940 e 1950 ficaram conhecidas como a "era de ouro do rádio" no Brasil. As rádios funcionavam como "veículo integrado ao contexto histórico em que estavam inseridas, utilizando e difundindo padrões de comportamento, estéticos, de vida, de sensibilidades e formas de sociabilidade urbanas e 'modernas' " (Matos \& Faria, 1996, p.43), ocupando grande espaço na vida das pessoas. Além disso, é importante considerar que, apesar de a indústria cultural ainda estar num estágio embrionário nessa época, as composições 
"alcançaram impressionante sucesso, o que deve significar que encontraram repercussão no imaginário popular" (Oliven, 1987, p.62).

Quanto ao contexto do relacionamento conjugal, convém destacar que nas décadas de 1940 e 1950 os papéis masculino e feminino eram rigidamente definidos, cabendo ao homem as atribuições relacionadas ao público, e à mulher aquelas relacionadas ao privado. O casamento tinha grande importância na vida de todos, e, em especial, das mulheres, já que seu papel girava em torno de ser esposa, mãe e dona de casa (Bassanezi, 2002). Segundo Matos (1997), nas décadas de 1940 e 1950 "as relações homem-mulher ainda se sedimentavam basicamente num pacto conjugal, pelo qual o homem deveria assumir o papel de provedor-trabalhador em troca do afeto exclusivo da mulher, que deveria zelar pelo conforto do lar e mostrar-se sincera e caseira" (p.133).

Nessa época, a mulher na família era considerada dependente econômica e legal do marido, considerado "cabeça do casal", refletindo uma desigualdade simbólica, baseada na ideia de uma natureza feminina oposta e subordinada à masculina. Trata-se de uma diferença de atribuições e, ao mesmo tempo, de uma escala de valores sobre as atividades exercidas por cada um dos gêneros, de forma que o trabalho da esposa não era considerado um trabalho, já que não era remunerado como o do marido (Vaitsman, 1994). Nem sempre a forma de se compreenderem os papéis de marido e esposa e de vivenciar o relacionamento conjugal foi essa, que foi se consolidando ao longo da história, de acordo com o contexto social, econômico, político e cultural, através de trocas e práticas sociais, alcançando significado partilhado socialmente, o que possibilitava aos indivíduos compreender o cotidiano relativo ao tema, bem como valores e normas sociais associados.

Como as músicas populares eram objeto de especial atenção nesse momento da história do país, atingindo grande parcela da população, e como a questão do relacionamento amoroso/conjugal sempre foi tema frequente na música brasileira, é provável que as canções contribuíssem para a forma como as pessoas significavam o casamento e os papéis de marido e esposa, além de influenciar seus comportamentos. Essas canções, ao mesmo tempo, eram influenciadas pelo modo como a vida conjugal era percebida, compreendida e experienciada na sociedade. Na verdade, as canções populares das décadas de 1940 e 1950 veiculavam, mantinham e recriavam representações sociais de marido e esposa, que se manifestavam nos comportamentos e práticas sociais do grupo, ao mesmo tempo que eram influenciadas por essas práticas.

O que se pretendeu foi conhecer, a partir da análise de letras de canções, como os papéis do marido e da esposa eram concebidos e vivenciados nas décadas de 1940 e 1950, pela ótica da perspectiva psicossociológica desenvolvida por Serge Moscovici. Essa abordagem tem como marco inicial o livro "A representação Social da Psicanálise", adaptação de sua tese de doutorado, publicada originalmente em 1961, em que ele descreve uma investigação sobre a concepção que os parisienses têm da psicanálise - valendo-se de entrevistas e de material da imprensa -, e estabelece o conceito de representação social (Moscovici, 1978).

\section{Senso comum e representações sociais}

Com o conceito de representação social, Moscovici se propôs à análise dos processos pelos quais os indivíduos, em interação, produzem teorias sobre os objetos sociais, viabilizando a comunicação e a organização dos comportamentos (Vala, 1997). A representação social, segundo Moscovici (1978), consiste numa "modalidade de conhecimento particular que tem por função a elaboração de comportamentos e a comunicação entre indivíduos" (p.27). É ela "um corpus organizado de conhecimento e uma das atividades psíquicas graças às quais os homens tornam inteligível a realidade física e social, inserem-se num grupo ou numa ligação cotidiana de trocas, e liberam os poderes de sua imaginação" (p.28). A proposta moscoviciana não pressupõe dicotomia entre psicológico e social, pois os processos cognitivos e afetivos, ou seja, os processos psicológicos, são a base da compreensão da realidade e estão integrados ao social, são parte dele, de forma que o social não é considerado apenas um "cenário". 
Sá (1998) destacou que as representações sociais constituem modalidade de pensamento prático, que emerge das práticas em vigor na sociedade e na cultura, alimentando-as, perpetuando-as ou contribuindo para a sua própria transformação. Jodelet (2001) conceitua a representação social como "uma forma de conhecimento, socialmente elaborada e partilhada, com um objetivo prático, e que contribui para a construção de uma realidade comum a um conjunto social" (p.22).

As representações sociais remetem à produção de sentido que permite ao indivíduo e ao grupo dar significado às suas condutas e ações e compreender a realidade através de seus referenciais, possibilitando que o indivíduo se adapte e se localize nessa realidade (Abric, 2000). Assim, as representações sociais acerca de determinado objeto orientam as ações, comportamentos e práticas sociais, no que se refere a esse objeto, o que varia de acordo com o grau de pertença dos indivíduos aos grupos em que estão inseridos e, ainda, de acordo com o contexto histórico-social-cultural.

Quando se diz que um grupo tem uma representação específica acerca de certo objeto, não se pretende que todos no grupo signifiquem o objeto da mesma forma. Há uma base comum de elementos compartilhados - fortes, significativos e sustentadores da identidade do grupo -, ao lado de elementos que são particulares, embora sejam determinados pelas circunstâncias e pelo tipo de inserção no grupo. Assim, uma representação social comporta, muitas vezes, elementos aparentemente contraditórios.

Assim como as representações podem influenciar as práticas sociais, estas também exercem sobre as primeiras sua influência, de modo que ambas, em relação dialética e não de dependência causal, estão mutuamente implicadas na construção uma da outra, sempre em articulação com outras representações e práticas relacionadas a elas, o que faculta falar em rede de representações e de práticas. As representações atuam como guia para as práticas, e essas como agentes na transformação das representações, e não apenas como reflexo das mesmas. Na relação entre representação e prática, os indivíduos têm papel ativo, já que as repre- sentações sociais não ditam as ações, mas apenas definem as possíveis condições da ação (Rouquette, 2000).

Tal consideração exclui a possibilidade de que representações e práticas sociais sejam tratadas como idênticas, ao mesmo tempo que também impede que sejam entendidas como coisas totalmente distanciadas, visto que constituem, na realidade, fenômenos de naturezas diferentes, que estão interligados. As práticas sociais se constituem pelas relações e hábitos cotidianos, e se concretizam por ações, apesar de não serem apenas ações independentes, sendo necessário que apresentem significado, isto é, que estejam conectadas a uma rede simbólica. As representações sociais, por sua vez, não são simples reprodução ou reflexo das práticas sociais e do mundo exterior, mas envolvem atividade de reconstrução da realidade, de organização significante, adquirindo condição de realidade natural para as pessoas.

Com base nas considerações prévias, pode-se afirmar que a Teoria das Representações Sociais, marcada pela complexidade, dinamismo e historicidade, pode contribuir para os objetivos da presente pesquisa.

\section{Método}

\section{Procedimentos}

Foram selecionadas 306 letras de músicas populares, gravadas no período entre 1940 e 1960, que traziam informações sobre os papéis masculinos e femininos e sobre a relação homem-mulher no contexto conjugal. Predominaram canções cujos compositores são homens (apenas 10 canções foram compostas por mulheres, 8 delas em parcerias com homens). Preponderantemente, essas canções podem ser classificadas na modalidade samba-canção: estilo mais lento que o samba tradicional, abolerado, centrado na temática da "dor de cotovelo" (expressão de sofrimento pelas dificuldades ou perdas amorosas) que, à época, substituiu a cadência mais tradicional do samba (Matos \& Faria, 1996). 
Foram examinadas letras de músicas gravadas entre os anos de 1940 e 1960 em acervos fonográficos e em livros sobre cantores e compositores da época. O procedimento adotado foi a leitura ou audição de todas as letras do período de interesse que fossem encontradas, selecionando-as de acordo com os objetivos do presente estudo. Na organização das letras foram estabelecidos dois períodos conforme o ano de composição/gravação das canções: primeiro período, de 1940 a 1949; e segundo período, de 1950 a 1960. Do primeiro período constaram 177 letras $(57,84 \%)$, e do segundo período 129 letras $(42,16 \%)$.

Na análise, foi empregado o software Analyse Lexicale par Contexte d'um Ensemble de Segments de Text (Alceste), criado por Max Reinert (1990). O instrumento busca "distinguir classes de palavras que representam diferentes formas de discurso a respeito do tópico de interesse" (Kronberger \& Wagner, 2002, p.427), de forma integrada com a Análise de Conteúdo, proposta por Bardin (1977), com os cuidados metodológicos especialmente requeridos pela pesquisa com letras de músicas (Menandro e Nascimento, 2007).

O Alceste reconhece as Unidades de Contexto Iniciais $(\mathrm{UCI})$, constituídas pelas letras de músicas, no caso, e divide cada corpus em segmentos de texto (Unidade de Contexto Elementar [UCE]), agrupando, a seguir, as ocorrências de palavras de mesma raiz e efetuando o cálculo das respectivas frequências. Na sequência, realiza análise denominada Classificação Hierárquica Descendente (CHD), cruzando os segmentos de texto de modo a conseguir classes de UCE que compartilhem vocábulos, ao mesmo tempo que se diferenciam dos outros conjuntos de UCE, chegando a uma hierarquia de classes, que também são apresentadas sob a forma de árvore - dendrograma (Teixeira, Schulze, \& Camargo, 2002). "O dendrograma e os índices de compartilhamento possibilitam verificar a ligação entre as classes (forte ou fraca) e a representatividade de cada classe dentro do corpus avaliado" (Martins, Trindade, \& Almeida, 2003).

Através da CHD o pesquisador tem acesso às classes léxico-semânticas, compostas de conjuntos de palavras associadas significativamente a determinada classe, assim como às UCE típicas de cada classe, o que faculta recuperar o contexto de significação/ocorrência de cada palavra (Teixeira et al., 2002).

Camargo (2005) propõe que as classes resultantes do processamento do Alceste podem ser consideradas representações sociais ou somente aspectos de uma única representação, a depender de seu conteúdo e sua relação com fatores relacionados aos objetivos do estudo.

Além da Classificação Hierárquica Descendente, o Alceste executa Análise Fatorial de Correspondência (AFC), que possibilita uma projeção das classes resultantes da CHD e das posições das variáveis em um plano fatorial.

Ao fim da análise, o Alceste fornece relatório detalhando as operações realizadas. É sobre tal relatório que o pesquisador se debruça, para interpretá-lo. O programa, é claro, não lida com o sentido do texto, trabalhando apenas com os contextos lexicais. Logo, as contribuições do Alceste e do pesquisador devem ser complementares (Menandro, 2004).

Do relatório gerado serão apresentadas adiante as classes obtidas (com seus respectivos vocabulários e valor do $\chi^{2}$, que, no caso, expressa a força da associação entre palavras e a classe em que foi incluída), os percentuais de material compartilhado entre classes, o dendrograma resultante da CHD, e algumas UCE características de cada uma das classes, possibilitando a contextualização das mesmas.

\section{Resultados e Discussão}

O Alceste efetuou sua análise, gerando um conjunto de UCE, do qual analisou $74,57 \%$ das unidades. O índice percentual de UCE analisadas, segundo Kronberger e Wagner (2002), tem grande importância para a garantia de qualidade e alcance da análise. Quando esse percentual é igual ou superior a 70,00\%, entende-se que há garantia de maior estabilidade das classes e de uma análise mais apurada. A análise das letras de canções indicou a existência de quatro classes, como se pode observar no dendrograma apresentado na Figura 1. 


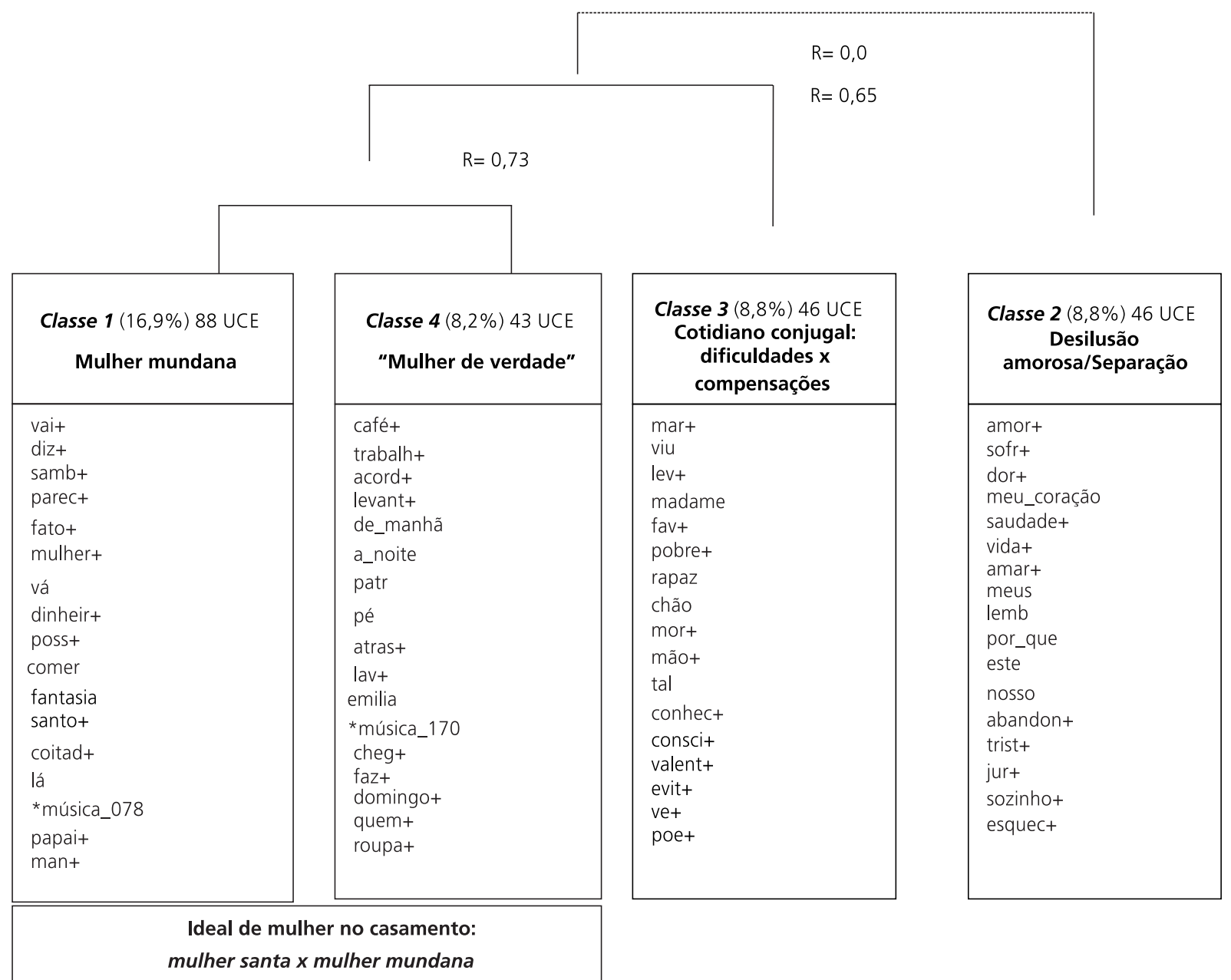

Papel feminino e masculino no casamento: real $x$ ideal

Figura 1. Dendrograma da distribuição das classes (nomeadas de acordo com o sentido dos contextos), com a contribuição percentual de cada uma no conteúdo analisado (quantidade de Unidade de Contexto Elementar [UCE]), com os índices de associação entre as mesmas (R), e com os 17 termos principais de cada classe (obtidos a partir do $\chi^{2}$ ).

Nota: *Nas classes 1 e 4, a nomeação de suas canções ("música_078 e *música_170) indica que sua contribuição foi marcante para essas classes. Nos termos seguidos pelo sinal +, foi considerado o radical da palavra, abrangendo diversos termos associados (exemplo: amor, amores, amoroso, amorosa, amorzinho).

O dendrograma apresenta a distribuição das classes (nomeadas de acordo com o sentido dos contextos definidos pela análise), o percentual representado por cada uma delas no conteúdo analisado, os índices de associação entre as mesmas e as 17 palavras ou radicais principais de cada classe (obtidas a partir do $\chi^{2}$, frequência e percentual de contribuição na classe), dispostas em ordem decrescente segundo o valor do $\chi^{2}$.

Em muitos casos as palavras constantes do dendrograma podem parecer, por si sós, esclarecedoras do sentido das classes a elas relacionadas.
Contudo, mesmo quando isso ocorre, é necessário que o pesquisador analise o contexto de significação/ocorrência das palavras para compreensão mais coerente das classes. No caso do presente estudo, as palavras principais apresentadas no dendrograma não são totalmente esclarecedoras, o que exigiu leitura/análise cuidadosa das UCE e também das UCI (letras das músicas) para o entendimento adequado das classes.

Como se pode observar na Figura 1, as classes 1, 3 e 4 estão associadas, formando um 
subcorpus que recebeu a denominação Papel feminino e masculino no casamento: real $x$ ideal. Podem ser consideradas como um eixo na organização das representações sociais de marido e de esposa. Já a classe 2 constitui outro eixo, por não apresentar ligação com as demais classes; foi nomeada Desilusão amorosa/separação.

O subgrupamento constituído pelas classes 1 e 4 foi designado Ideal de mulher no casamento: mulher santa $\mathbf{x}$ mulher mundana, e traz conteúdos relacionados ao cotidiano familiar/conjugal, apresentando indicações do papel do homem e da mulher no contexto do casamento, sobretudo os papéis femininos. Contrasta como a mulher deve ser e como ela não deve ser. Assim, revela o ideal de mulher no contexto do relacionamento conjugal, que corresponde à mulher dona de casa, afeita às atividades domésticas, com qualidades maternais, resignada, submissa, conferindo segurança ao homem (elementos presentes na classe 4). Já o homem aparece como trabalhador/provedor e necessitado de mulher dedicada e compreensiva, que cuide dele (exemplo, "Ihe acorde na hora de trabalhar"), fator do qual depende o sucesso do casamento.

Na classe 1, denominada Mulher mundana, evidencia-se a condição oposta ao ideal de mulher/esposa: é a que sai para se divertir, vai ao samba, não se dedica integralmente à casa e ao marido, trabalha, não respeita o homem - o que não pode ser aceito. Logo, indica decepção do homem em relação à mulher/companheira, que não é o que ele esperava que fosse e que ele idealizava. O homem é retratado como aquele que faz tudo pela mulher e sente-se ridicularizado, já ela não "o obedece" e não valoriza o lar construído por ele.

A seguir são apresentados alguns fragmentos de letras, selecionados pelo Alceste como UCE significativas para a composição da Classe 1, e que ajudam a compreender o sentido da classe, juntamente com as principais palavras e radicais da classe:

Não tem mais jeito, mulher quando perde a vergonha e o respeito, não tem mais jeito ("Consulta teu travesseiro", de Herivelto Martins e Benedito Lacerda, 1951).

Desacatou-me, vou reprovar-te. Guardo na memória, hei de vingar-me. Diga por que você me deixa em casa e vai para a orgia, desobedece-me, perca esta mania. Um desacato ninguém pode aturar. Mulher que abandona a casa e vai para o morro sambar. Não quero que a mulher faça como fez outra vez ("Desacato", de Murilo Caldas e Wilson Batista, 1956).

Agora aqui da minha vida termino dando cabo. A mulher com quem me casei não é mulher, isso é o diabo. A minha mobilia, meu trem de cozinha, a mulher tudo quebrou. Foi à delegacia dizer ao comissário: meu marido me espancou, e ele acreditou ("Bilhete branco", de Henrique Gonçalez, 1941).

Em contrapartida, a classe 4, designada "Mulher de verdade", contempla a ideia da mulher ideal, dedicada à casa e ao marido trabalhador, chefe de família. É a valorização da mulher do lar (a Emília e a Amélia, cantadas nas canções "Emília", de Haroldo Lobo e Wilson Batista, e "Ai que saudades da Amélia", de Mário Lago e Ataulfo Alves, ambas de 1942), e a apologia do casamento. A responsabilidade pelo sucesso ou fracasso do casamento parece depender absolutamente da mulher. Uma das letras que aparece como representativa dessa classe (reproduzida a seguir) explicita bem a ideia predominante:

A minha patroa é boa, faz tudo pra me agradar. Sabendo que eu ganho pouco, trabalha pra me ajudar. Passa o dia numa tina, passa a noite a costurar. E aos domingos quando vem da missa engoma a nossa roupa branca e vamos passear (isso é verdade). E quando chega na segunda-feira levanto alegre para trabalhar. Assim passamos a semana inteira vivendo apenas para o nosso lar. Mulher assim é uma felicidade que muita gente vive a procurar. Por isso eu te digo com sinceridade: mulher igual a ela para mim não há ("Minha patroa é boa", de Waldemar Silva e Estanislau Silva, 1944).

O modelo familiar predominante nas décadas de 1940 e 1950, em que a mulher devia dedicar-se às tarefas do lar e o homem devia ser o provedor financeiro, aparece retratado nas letras de músicas. 
O mesmo modelo figurava também em jornais e revistas da época, principalmente naquelas dirigidas às mulheres da classe média, o que acabava repercutindo no controle dos comportamentos. Revistas e jornais apresentavam valores e regras de comportamento; tratavam de assuntos como casamento, sexualidade, felicidade conjugal, trabalho feminino, entre outros, prescrevendo normas sobre como se devia agir e ser, influenciando as mulheres nesse momento histórico. Ao mesmo tempo, essas publicações foram influenciadas pelas mudanças sociais que essas mulheres vivenciaram (Bassanezi, 2002).

Nesse sentido, como propuseram Matos e Faria (1996), a relação cotidiana entre homem e mulher no contexto do casamento parece refletir as relações sociais da época, nas quais homens e mulheres tinham direitos e deveres desiguais, o que se sustenta numa relação de dominação de gênero característica daquele momento da história brasileira.

Já a classe 3, nomeada Cotidiano conjugal: dificuldades $\mathbf{x}$ compensações, abrange conteúdos que sugerem a decepção da mulher em relação ao casamento e/ou ao companheiro, salientando-se a questão da traição masculina e o desespero da mulher em perder o marido para outra - até suicídio aparece como possibilidade diante da frustração/perda. Tal comportamento pode estar relacionado à dependência social e financeira em relação ao homem, característica da época.

Hoje não tem ensaio não, na escola de samba. O morro está triste e o pandeiro calado. Maria da Penha, a porta-bandeira, ateou fogo às vestes por causa do namorado ("Mãe solteira", de Wilson Batista e Jorge de Castro, 1954).

Tenho um recado para você que a Maria mandou. Não digo aqui porque é particular. A pobrezinha estava aflita, quase se jogou no mar. Eu vi que não era fita, consegui tudo evitar. A Maria contou para mim que quase mudou de cor quando viu você na saída do baile com a Leonor ("O recado que a Maria mandou", de Haroldo Lobo e Wilson Batista, 1945). sa classe a ideia da mulher consumista, que muda de vida e se torna "madame", e não quer mais saber da vida de dificuldades que tinha antes, o que desaponta o homem. O fragmento abaixo exemplifica bem o caso:

Nunca vi fazer tanta exigência, nem fazer o que você me faz, você não sabe o que é consciência, não sabe que sou um pobre rapaz. Você só pensa em luxo e riqueza, tudo o que você vê você quer, ah, meu Deus, que saudades da Amélia, aquilo sim é que era mulher ("Ai que saudades da Amélia", de Mário Lago e Ataulfo Alves, 1942).

Já a classe 2, por constituir outro eixo na organização da representação social, apresenta conteúdos distanciados daqueles das classes anteriores, que giravam em torno do cotidiano conjugal. $\mathrm{Na}$ classe 2, que apresenta o maior número de UCE (345), predomina o sofrimento do homem pela ausência da mulher amada - ele sofre por amor e saudade da mulher que o abandonou. Logo, é classe constituída, fundamentalmente, por conteúdos sobre separação, tendo sido denominada Desilusão amorosa/separação. Os exemplos ressaltam a condição do homem iludido por juras de amor, que se decepcionou e agora sofre por estar só, abandonado, implorando pelo retorno da mulher.

Volta para esse lar que ainda é seu, volta, nosso amor não morreu. Sem você já não tenho alegria, não suporto esta casa vazia. Volta, pois o meu rouxinol já não canta no romper do dia ("Nosso amor não morreu", de Alcides Rosa e Sebastião Gomes, 1945).

A sua promessa faliu, sua jura também se quebrou, mentiste ao meu coração, mentiste ao nosso senhor. Eu sei que você vive bem sem ter os carinhos meus, mas não podes ser feliz sem a graça de Deus ("Mentirosa", de Custódio Mesquita e Mário Lago, 1941).

Eu fiz por ela o que pude, muito me sacrifiquei. $E$ ante a sua atitude, quantos conselhos the dei, e ela com frases tão frias e seus carinhos profanos, destruiu em poucos 
dias, um amor de tantos anos ("Tantos Anos", de Nelson Gonçalves e René Bittencourt, 1950).

Destaca-se nessa classe a presença do homem idealizado, romântico e dono de um amor sem igual; homem que age pelo coração, chora por amor, pela perda da amada, e implora humildemente pela volta da companheira. Trata-se de uma idealização idêntica à constatada por Menandro et al. (2002), em estudo com canções mais recentes identificadas como "bregas" por envolverem melodia, arranjos e letras que repetem fórmulas muito exploradas. A mulher aparece como a que abandona, que é indiferente, mas ao mesmo tempo como a "santa" sem a qual o homem não consegue viver. Assim, ficam evidentes as contradições que permeiam as representações sociais dos papéis de gênero no casamento.

A partir da análise de conteúdo das letras de canções, foi possível confirmar a presença de diversas proposições culturalmente aceitas sobre casamento e vida conjugal, que provavelmente estão em acordo com o que se pensava na época, e que auxiliam a compreensão das representações descritas. Exemplos de regras e imposições, selecionadas das músicas, às vezes com pequenas alterações na redação, são arrolados a seguir:

O casamento é sagrado e precisa ser respeitado; não importava se os noivos não se gostem, primeiro casem pra depois se amar; sofrimento da mulher por ser solteirona; medo de "ficar para titia" ou ter que ir para um convento; mulher que muito namora não encontra casamento; mulher séria (casada) não enxerga, não fala, não ouve nada; casamento é loteria difícil de acertar; é melhor brigar juntos do que chorar separados; sociedade não aceita que quem já foi casado se case novamente; ter que viver juntos, mesmo sem querer, em virtude do preconceito da sociedade que condena a separação; homem é o chefe de familia e não pode ficar sem trabalhar; homem casado não pode levar vida de solteiro, não deve ficar na farra.
Como os resultados evidenciam, a forma de ser homem e ser mulher no contexto do casamento e na vida em geral é construção resultante de fatores sociais, históricos e culturais, não podendo ser tratada de modo naturalizado, apoiado na natureza biológica e imutável dos gêneros. Para o entendimento de tal processo no período que o estudo focaliza, as canções sobre o tema produzidas nas décadas de 1940 e 1950 se revelaram fontes de informação adequada sobre os papéis feminino e masculino no casamento.

As letras das canções fornecem claras indicações sobre como o papel da mulher no casamento era compreendido no período, mostrando como as mulheres deveriam agir naquele contexto. Evidenciam uma representação social de esposa que tem forte ligação com a representação social da mulher para a sociedade da época. Ao mesmo tempo, há indicações de representação social de esposo, conforme as quais o homem deve ser trabalhador e autoridade familiar. São representações justificadoras e orientadoras das relações entre homem e mulher no âmbito do casamento, incorporadas ao senso comum.

Não se pode perder de vista que, no universo de canções analisado (306), apenas 10 letras foram compostas por mulheres - e quase sempre em parceria com homens. Assim, o que se encontra nas letras é o discurso do homem falando sobre si, sobre a mulher, sobre o casamento, predominando o discurso masculino nas letras, o que está de acordo com o fato de que a mulher naquela época estava ainda começando a conquistar espaço na cena pública, até então lugar masculino por excelência.

A esse respeito Santa Cruz (1992) escreve: "Se estabelecia uma relação ventríloqua entre criador (homem) e a criatura (mulher). A voz da mulher foi usada somente para reproduzir um discurso ... portador de uma ideologia sexista e indicador do homem como um ser superior no contexto geral da humanidade" (p.15).

Del Priore (1995) argumenta que, no período de colonização do Brasil, quando os papéis femininos ainda não estavam claramente definidos, delineou-se um processo de convencimento das 
mulheres em favor da maternidade. Por muitos anos, foi interesse do Estado e da Igreja que as mulheres assumissem o modelo de identidade "casada, mãe, afeita à domesticidade, à piedade religiosa, preocupada em consolidar a família" (Del Priore, 1995, p.81), modelo esse que deveria ser transmitido por elas às gerações seguintes. É certo que estão implicadas submissão e dependência.

Nas letras de canções, esse modelo está presente em vários detalhes, como é visível nos excertos apresentados como ilustração:

O casamento é sagrado; ela é a dona de tudo, ela é a rainha do lar; a mulher é apenas a mulher dominada pelas leis da natureza; a mulher que é mulher não deixa o lar à toa e se o homem errar perdoa; dez anos depois nós dois não somos dois, somos dez; vinte e cinco anos vamos festejar de união.

Tais representações sociais de marido e esposa foram construídas em momentos históricos específicos, em que a mulher devia voltar-se para o lar, os filhos e o marido, enquanto o homem devia direcionar-se para a rua e o trabalho fora, o que possibilitava aos indivíduos darem significado a seus comportamentos e condutas.

Essa perspectiva, entretanto, não era a única disponível, e muitas letras de canções o registram, apresentando abordagens discrepantes. Algumas questionam diretamente o casamento e exploram suas inconveniências, salientando as vantagens da vida de solteiro. Outras denunciam a hipocrisia do modelo, mencionando relacionamentos extraconjugais e violência. Outras, ainda, saúdam ou receiam a possibilidade do divórcio, tema já mencionado na época. Outras mais caracterizam a mulher como perigosa, inconstante e volúvel, e brincam com a impossibilidade de entendê-la. Outras também enfatizam a ingenuidade e os bons propósitos dos homens, que ainda assim são desprezados. Outras, por sua vez, louvam ou criticam os homens exploradores que querem viver às custas de suas mulheres.

O que foi dito acima evidencia que todos os elementos de representações sociais espelhados nas canções emergiram das práticas sociais vigentes no contexto histórico-social ao qual elas se referem, passando a ser parte das condições mantenedoras dessas mesmas práticas. Alguns aspectos dessas práticas e desses elementos de representações sociais ainda podem ser identificados hoje, na forma das assimetrias que perduram nas relações conjugais e familiares entre homens e mulheres. Outros temas, como casamento indissolúvel, submissão absoluta da mulher, dedicação exclusiva ao lar, e exclusividade na condição de provedor, parecem mais apartados da realidade atual de grande parte da sociedade brasileira.

\section{Referências}

Abric, J. C. (2000). A abordagem estrutural das representações sociais. In A. S. P. Moreira \& D. C. Oliveira (Orgs.), Estudos interdisciplinares em representação social (pp.39-46). Goiânia: AB.

Augras, M. R. A. (1998). O Brasil do samba-enredo. Rio de Janeiro: Fundação Getúlio Vargas.

Almeida Prado, D. (1990). Três movimentos (musicais) em torno de 1930. Revista USP, 4, 13-16.

Bardin, L. (1977). Análise de conteúdo. Lisboa: Edições 70.

Bassanezi, C. (2002). Mulheres dos anos dourados. In M. Del Priore (Org.), História das mulheres no Brasil (pp.607-639). São Paulo: Contexto.

Beltrão Jr., S. (1993). A musa-mulher na canção brasileira. São Paulo: Estação Liberdade.

Camargo, B. V. (2005). Alceste: um programa informático de análise quantitativa de dados textuais. In A. S. P. Moreira (Org.), Perspectivas teórico-metodológicas em representações sociais (pp.511-539). João Pessoa: UFPB.

Costa, N. M. (2004). De amor, cotidiano e outras falas: o discurso da musica brasileira popular. São Paulo: Arte e Ciência.

Del Priore, M. (1995). Ao sul do corpo: condição feminina, maternidades e mentalidades no Brasil Colônia. Rio de Janeiro: José Olyimpio.

Dias, R. M. (1994). As paixões tristes: Lupicínio e a dor-de-cotovelo. Rio de Janeiro: Leviatã.

Diniz Neto, O., \& Féres-Carneiro, T. (2005). Psicoterapia de casal na pós-modernidade: rupturas e possibilidades. Estudos de Psicologia (Campinas), 22(2), 133-141.

Faour, R. (2002). Revista do Rádio: cultura, fuxicos e moral nos anos dourados. Rio de Janeiro: Relume-Dumará.

Gomes, T. M. (1999). Estudos acadêmicos sobre a musica popular brasileira: levantamento bibliográfico e comentário introdutório. História: Questões \& Debates, 16(31), 95-111. 
Jodelet, D. (2001) Representações sociais: um domínio em expansão. In D. Jodelet (Org.), As representações sociais (pp.17-44). Rio de Janeiro: EdUERJ.

Kronberger, N., \& Wagner, W. (2002). Palavras-chave em contexto: análise estatística de textos. In M. W. Bauer \& G. Gaskell (Orgs.), Pesquisa Qualitativa com texto, imagem e som: um manual prático (pp.416-441). Petrópolis: Vozes.

Lenharo, A. (1995). Cantores do rádio: a trajetória de Nora Ney e Jorge Goulart e o meio artístico de seu tempo. Campinas: Unicamp.

Marques, J. (2000). Canção interrompida: as compositoras brasileiras dos anos 30/40. Gênero, 3(1), 41-47.

Martins, P. O., Trindade, Z. A., \& Almeida, A. M. O. (2003). O ter e o ser: representações sociais da adolescência entre adolescentes de inserção urbana e rural. Psicologia: Reflexão e Crítica, 16(3), 555-568.

Matos, M. I. S. (1997). Dolores Duran: experiências boêmias em Copacabana nos anos 1950. Rio de Janeiro: Bertrand Brasil.

Matos, M. I. S., \& Faria, F. A. (1996). Melodia e sintonia em Lupicínio Rodrigues: o feminino, o masculino e suas relações. Rio de Janeiro: Bertrand Brasil.

Matos, M. I. S. (1999). O ébrio apaixonado: perfis de gênero no imaginário da MPB - 1930-1950. Imaginário, 5, 07-25.

Matos, M. I. S. (2000). Meu lar é o botequim: alcoolismo e masculinidade. São Paulo: Companhia Editorial Nacional.

Menandro, M. C. S. (2004). Gente jovem reunida: um estudo de representações sociais da adolescêncialjuventude a partir de textos jornalísticos (1968) 1974 - 1996/2002) (Tese de doutorado não-publicada). Universidade Federal do Espiríto Santo, Vitória.

Menandro, P. R. M., Pereira, J. F., Amim, I. D., \& Santos, S. M. (2002). Aspectos do relacionamento amoroso presentes em letras de músicas dirigidas à camada popular urbana. Arquivos Brasileiros de Psicologia, 54(1), 3-19.

Menandro, P. R. M., \& Nascimento, A. R. A. (2007). Análise de conteúdo de material documental pré-existente à investigação: o caso da musica popular. In M. M. P. Rodrigues \& P. R. M. Menandro (Orgs.), Lógicas metodológicas: trajetos de pesquisa em Psicologia (pp.207-224). Vitória: PPGP-UFES/GM Editora.

Moscovici, S. (1978). Representação social da psicanálise. Rio de Janeiro: Zahar.

Napolitano, M. (1999). O conceito de "MPB" nos anos 60. História: Questões \& Debates, 16(31), 11-30.
Napolitano, M. (2001). "Seguindo a canção: engajamento político e indústria cultural na MPB" (1959-1969). São Paulo: Annablume/Fapesp.

Nascimento, A. R. A. (2004). Memória dos verdes anos: saudade da infância na música popular brasileira uma investigação e uma proposta de análise de dados (Tese de doutorado não-publicada). Universidade Federal do Espiríto Santo, Vitória.

Nascimento, A. R. A., Barra, M. L. P., \& Januário, F. S. (2008). Respeitem, ao menos, os meus cabelos brancos: velhice e envelhecimento na canção brasileira (1927-2006). Arquivos Brasileiros de Psicologia, 60(2), 198-211.

Oliveira, J. S., \& Marcier, M. H. (1998). A palavra é: favela. In A. Zaluar \& M. Alvito (Orgs.), Um século de favela (pp.61-114). Rio de Janeiro: Fundação Getúlio Vargas.

Oliven, R. G. (1987). A mulher faz e desfaz o homem. Ciência Hoje, 7(37), 55-62.

Quintas, F. (2000). A mulher e a família no final do século $X X$. Recife: FJN/Massangana.

Reinert, M. (1990) Alceste: une méthodologie d'analyse des données textuelles et une application: Aurélia, de Gérard de Nerval. Bulletin de Méthodologie Sociologique, 26(1), 24-54.

Rouquette, M. L. (2000). Representações e práticas sociais: alguns elementos teóricos. In A. S. P. Moreira \& D. C. Oliveira (Orgs.), Estudos interdisciplinares em representação social (pp.39-46). Goiânia: AB.

Sá, C. P. (1998). A construção do objeto de pesquisa em representações sociais. Rio de Janeiro: EdUERJ.

Santa Cruz, M. A. (1992). A musa sem máscara: a imagem da mulher na cultura popular brasileira. Rio de Janeiro: Rosa dos Tempos.

Teixeira, M. C. T. V., Schulze, C. M. N., \& Camargo, B. V. (2002). Representações sociais sobre a saúde na velhice: um diagnóstico psicossocial na rede básica de saúde. Estudos de Psicologia, 7(2), 351-359.

Vaitsman, J. (1994). Flexíveis e plurais: identidade, casamento e família em circunstâncias pós-modernas. Rio de Janeiro: Rocco.

Vala, J. (1997). Representações sociais: para uma psicologia do pensamento social. In J. Vala \& M. B. Monteiro (Orgs.), Psicologia social (pp.353-384). Lisboa: Fundação Calouste Gulbenkian.

Vieira, J., \& Norberto, N. (1992). Herivelto Martins: uma escola de samba. Rio de Janeiro: Ensaio.

Recebido: outubro 7, 2013

Versão final: janeiro 24, 2014

Aprovado: fevereiro 17, 2014 
